\title{
Impact of Total Antithrombotic Effect on Bleeding Complications in Patients Receiving Multiple Antithrombotic Agents
}

Shinya Ichikawa, MD; Kengo Tsukahara, MD; Shinnosuke Kikuchi, MD; Yugo Minamimoto, MD; Yuichiro Kimura, MD; Kozo Okada, MD; Yasushi Matsuzawa, MD; Masaaki Konishi, MD; Nobuhiko Maejima, MD; Noriaki Iwahashi, MD; Kiyoshi Hibi, MD; Masami Kosuge, MD; Toshiaki Ebina, MD; Kouichi Tamura, MD; Kazuo Kimura, MD

Background: Few reports have evaluated the total antithrombotic effect of multiple antithrombotic agents.

Methods and Results: Thrombus formation was evaluated with the Total Thrombus-formation Analysis System (T-TAS ${ }^{\circledR}$ ) using 2 types of microchips in 145 patients with stable coronary artery disease receiving oral anticoagulants plus single- or dual-antiplatelet therapy. The PL-chip coated with collagen is designed for analysis of the platelet thrombus formation process under shear stress condition (18 $\mu \mathrm{L} / \mathrm{min})$. The AR-chip coated with collagen and tissue thromboplastin is designed for analysis of the fibrin-rich platelet thrombus formation process under shear stress condition $(4 \mu \mathrm{L} / \mathrm{min})$. The results were expressed as an area under the flow pressure curve ( $\mathrm{PL}_{18}-\mathrm{AUC}_{10}$ and $\mathrm{AR}_{4}-\mathrm{AUC}_{30}$, respectively). Bleeding events occurred in 43 patients during a 22-month follow-up. $\mathrm{AR}_{4}-\mathrm{AUC}_{30}$ was significantly lower in patients with bleeding events than in those without (584 [96-993] vs. 1,028 [756-1,252], $P=0.0003)$. Multivariate logistic regression analysis identified $\mathrm{AR}_{4}-\mathrm{AUC}_{30}$ (odds ratio 3.18) as a significant predictor of bleeding events, in addition to baseline anemia and usage of the standard dose of direct oral anticoagulants. However, $\mathrm{PL}_{18}-\mathrm{AUC}_{10}$ was not significantly related to bleeding events.

Conclusions: $A$ lower $\mathrm{AR}_{4}-\mathrm{AUC}_{30}$ level was associated with increasing risk of subsequent bleeding complications in patients with stable coronary artery disease who received multiple antithrombotic agents.

Key Words: Anticoagulants; Antiplatelet therapy; Coronary artery disease; Hemorrhage; Thrombogenicity

$\mathbf{L}$ ong-term treatment with oral anticoagulants is necessary in patients with mechanical heart valves, and in most with atrial fibrillation (AF) or venous thromboembolism. Approximately $20-30 \%$ of these patients have concomitant coronary artery disease (CAD) that requires percutaneous coronary intervention $(\mathrm{PCI})$ with stenting. ${ }^{1}$ Antiplatelet therapy has been a cornerstone of medical therapy in patients with CAD, but the combination of oral anticoagulants and antiplatelet therapy is associated with an increased risk of bleeding complications. Therefore, the optimum treatment in patients who have coexisting $\mathrm{CAD}$ and mechanical heart valves, $\mathrm{AF}$, or venous thromboembolism is unclear when thrombotic and bleeding risks are both taken into account. The treatment strategy for patients receiving multiple antithrombotic agents, oral anticoagulants plus single- or dual-antiplatelet therapy must balance the risk of a bleeding event with the expected benefit of thrombotic event reduction. The conventional therapy has been to combine all 3 drugs in a strategy known as triple therapy. However, this approach has resulted in excessive major bleeding, with rates of $2.2 \%$ within the first month and $4-12 \%$ within the first year of treatment. ${ }^{2}$

The WOEST (What Is the Optimal Antiplatelet and Anticoagulant Therapy in Patients with Oral Anticoagulation and Coronary Stenting) trial demonstrated that single-antiplatelet therapy with clopidogrel plus oral anticoagulation was associated with a significantly lower risk of bleeding complications than was triple therapy with aspirin, clopidogrel, and oral anticoagulation in patients undergoing PCI who required anticoagulation treatment. ${ }^{3}$ In addition, the PIONEER AF-PCI (Open-Label, Randomized, Controlled, Multicenter Study Exploring Two Treatment Strategies of Rivaroxaban and a Dose-

Received November 21, 2018; revised manuscript received March 7, 2019; accepted March 11, 2019; J-STAGE Advance Publication released online April 11, 2019 Time for primary review: 26 days

Division of Cardiology, Yokohama City University Medical Center, Yokohama (S.I., K. Tsukahara, S.K., Y. Minamimoto, Y.K., K.O., Y. Matsuzawa, M. Konishi, N.M., N.I., K.H., M. Kosuge, T.E., K.K.); Department of Medical Science and Cardiorenal Medicine, Yokohama City University Graduate School of Medicine, Yokohama (K. Tamura), Japan

Mailing address: Kengo Tsukahara, MD, Division of Cardiology, Yokohama City University Medical Center, 4-57 Urafune-cho, Minami-ku, Yokohama 232-0024, Japan. E-mail: k-tsuka@urahp.yokohama-cu.ac.jp

ISSN-1346-9843 All rights are reserved to the Japanese Circulation Society. For permissions, please e-mail: cj@j-circ.or.jp 


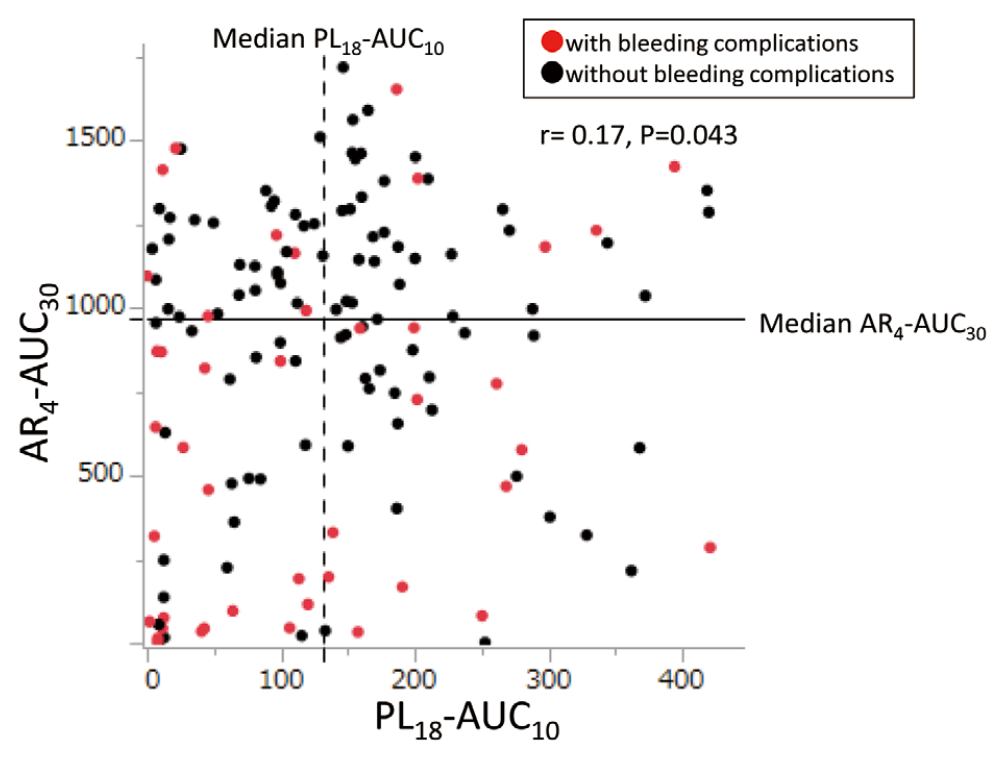

Figure 1. Individual $\mathrm{AR}_{4}-\mathrm{AUC}_{30}$ and $\mathrm{PL}_{18-}$ AUC 10 data for all study patients. The median values of $A R_{4}-A \cup C_{30}$ and $P L_{18}-A U C_{10}$ were 967 and 131, respectively. Red dots show patients with bleeding complications and black dots show patients without bleeding complications. $\mathrm{AR}_{4}-\mathrm{AUC}_{30}$, area under the flow pressure curve for the first $30 \mathrm{~min}$ for the AR-chip tested at a flow rate of $4 \mu \mathrm{L} / \mathrm{min}$; $\mathrm{PL}_{18}-\mathrm{A} \cup \mathrm{C}_{10}$, area under the flow pressure curve for the first $30 \mathrm{~min}$ for the PL-chip tested at a flow rate of $18 \mu \mathrm{L} / \mathrm{min}$.

Adjusted Oral Vitamin K Antagonist Treatment Strategy in Subjects with Atrial Fibrillation who Undergo Percutaneous Coronary Intervention) trial demonstrated that lowdose rivaroxaban plus single-antiplatelet therapy and very-low-dose rivaroxaban plus dual-antiplatelet therapy could significantly lower the risk of bleeding complications compared with conventional triple therapy with warfarin and dual-antiplatelet therapy. ${ }^{4}$ However, both trials showed that about $14-15 \%$ of patients receiving singleantiplatelet therapy plus anticoagulant agents had bleeding complications requiring medical attention. There may be an inter-individual variability in the response to antithrombotic agents, so assessment of antithrombotic effects is desirable to avoid bleeding complications, especially in patients receiving multiple antithrombotic agents. However, it is difficult to monitor the total antithrombotic effect using conventional methods, such as prothrombin time-international normalized ratio (PT-INR), activated partial thromboplastin time (aPTT), and platelet function tests in patients receiving multiple antithrombotic agents.

Recently, the Total Thrombus-formation Analysis System (T-TAS; Fujimori Kogyo Co Ltd., Japan), a microchip-based flow chamber system that can evaluate whole-blood thrombogenicity, was developed as an easyto-use system for quantitative analysis of thrombus formation. ${ }^{\mathbf{5}, \mathbf{6}} \mathrm{A}$ previous study reported that quantitative analysis of thrombus formation with T-TAS using the AR-chip was potentially useful for predicting bleeding events in AF patients undergoing catheter ablation. ${ }^{7}$ Thus, the aim of the present study was to evaluate the relationship between quantitative analysis of antithrombotic effects with T-TAS and subsequent bleeding complications in patients receiving multiple antithrombotic agents.

\section{Methods}

\section{Subjects}

Between September 2013 and May 2017, quantitative analysis of antithrombotic effects, using T-TAS, was performed in 145 patients with stable CAD (125 men; mean age, 74 years) who were undergoing oral anticoagulation treatment in addition to single- or dual-antiplatelet therapy. In this retrospective and observational study, all study patients were on oral anticoagulation treatment with direct oral anticoagulants (DOACs) or vitamin $\mathrm{K}$ antagonists plus antiplatelet therapy with $100 \mathrm{mg} /$ day of aspirin and/or a Japanese standard dose of a P2Y12 receptor inhibitor ( $75 \mathrm{mg} /$ day clopidogrel or $3.75 \mathrm{mg} /$ day prasugrel) for at least 7 days. Oral anticoagulants and antiplatelet agents were prescribed at each doctor's discretion. Exclusion criteria included any bleeding events within 30 days before enrollment, a hemoglobin level $<7 \mathrm{~g} / \mathrm{dL}$ or $>18 \mathrm{~g} / \mathrm{dL}$, a platelet count $<50,000 / \mu \mathrm{L}$ or $>500,000 / \mu \mathrm{L}$, hematologic or malignant disease, hemodialysis, severe liver dysfunction, and administration of a loading dose of P2Y12 receptor inhibitors, or fibrinolytic agents within 7 days before enrollment. The study protocol was approved by the Ethics Committee of Yokohama City University. Written, comprehensive, informed consent was given by all patients.

\section{Collection of Blood Samples}

Blood samples were collected as described in detail previously. ${ }^{8}$ Briefly, blood samples were collected from the antecubital vein with a 21-gauge needle into the following tubes: hirudin-containing blood sampling tube (MP0600 [Verum Diagnostica]; final concentration of hirudin $25 \mu \mathrm{g} / \mathrm{mL}$ ); blood collection tubes (VP-CA050K70, Venoject II; Terumo), and syringe containing $0.11 \mathrm{~mL}$ of $3.8 \%$ sodium citrate solution. Whole-blood samples were kept at room temperature for $1 \mathrm{~h}$, and thereafter thrombus formation was measured with T-TAS.

All blood samples of patients receiving DOACs were obtained 2-4h after taking DOACs, and those of patients receiving vitamin $\mathrm{K}$ antagonists were obtained after warfarin doses were fixed in the steady state.

\section{Measurement of Thrombogenicity Using T-TAS}

T-TAS is an automated, microchip-based flow chamber 


\begin{tabular}{|c|c|c|c|}
\hline & $\begin{array}{l}\text { With bleeding events } \\
\qquad(n=43)\end{array}$ & $\begin{array}{l}\text { Without bleeding events } \\
\qquad(n=102)\end{array}$ & $P$ value \\
\hline Male (\%) & $39(91)$ & $86(84)$ & 0.31 \\
\hline Age (years) & $75 \pm 9$ & $74 \pm 10$ & 0.70 \\
\hline BMI $\left(\mathrm{kg} / \mathrm{m}^{2}\right)$ & $22.8 \pm 2.7$ & $23.4 \pm 3.6$ & 0.36 \\
\hline Current smoking (\%) & $10(23)$ & $15(15)$ & 0.21 \\
\hline Hypertension (\%) & $33(77)$ & $80(78)$ & 0.82 \\
\hline Dyslipidemia (\%) & $27(63)$ & $63(62)$ & 0.91 \\
\hline Diabetes mellitus (\%) & $17(40)$ & $43(42)$ & 0.77 \\
\hline Prior MI (\%) & $28(65)$ & $72(71)$ & 0.52 \\
\hline Prior $\mathrm{PCl}(\%)$ & $31(72)$ & $79(77)$ & 0.49 \\
\hline Prior stroke/TIA (\%) & $4(9)$ & $11(11)$ & 0.79 \\
\hline Stent implantation (\%) & $26(60)$ & $67(66)$ & 0.55 \\
\hline DES (\%) & $16(37)$ & $44(43)$ & 0.51 \\
\hline BMS (\%) & $11(26)$ & $30(29)$ & 0.64 \\
\hline Atrial fibrillation (\%) & $38(88)$ & $89(87)$ & 0.85 \\
\hline Peripheral artery disease (\%) & $1(2)$ & $6(6)$ & 0.36 \\
\hline CHADS2 score & $2.2 \pm 1.2$ & $2.4 \pm 1.2$ & 0.37 \\
\hline$\geq 2(\%)$ & $33(77)$ & $74(73)$ & 0.60 \\
\hline HAS-BLED score & $2.5 \pm 0.9$ & $2.3 \pm 0.9$ & 0.14 \\
\hline$\geq 3(\%)$ & $19(44)$ & $28(27)$ & 0.049 \\
\hline Baseline anemia (\%) & $28(65)$ & $38(37)$ & 0.0021 \\
\hline Platelet count $\left(\times 10^{4} / \mu \mathrm{L}\right)$ & $18.5 \pm 6.5$ & $19.3 \pm 5.3$ & 0.47 \\
\hline eGFR $<60 \mathrm{~mL} / \mathrm{min} / 1.73 \mathrm{~m}^{2}(\%)$ & $29(67)$ & $68(67)$ & 0.93 \\
\hline PT-INR & $1.5[1.3-2.0]$ & $1.7[1.4-1.9]$ & 0.61 \\
\hline aPTT (s) & $39.3[33.8-46.9]$ & $37.4[33.3-41.8]$ & 0.11 \\
\hline Aspirin (\%) & $34(79)$ & $90(88)$ & 0.15 \\
\hline P2Y12 inhibitors (\%) & $23(53)$ & $42(41)$ & 0.17 \\
\hline Clopidogrel (\%) & $17(40)$ & $39(38)$ & 0.88 \\
\hline Prasugrel (\%) & $6(14)$ & $3(3)$ & 0.012 \\
\hline ARB/ACEI (\%) & $35(81)$ & $68(67)$ & 0.074 \\
\hline Statins (\%) & $34(79)$ & $86(84)$ & 0.45 \\
\hline$\beta$-blockers (\%) & $31(72)$ & $77(75)$ & 0.67 \\
\hline Calcium-channel blockers (\%) & $12(28)$ & $40(39)$ & 0.19 \\
\hline Oral antidiabetic agents (\%) & $9(21)$ & $29(28)$ & 0.35 \\
\hline Proton-pump inhibitors (\%) & $37(86)$ & $79(77)$ & 0.24 \\
\hline DOACs (\%) & $27(63)$ & $42(41)$ & 0.017 \\
\hline Standard dose of DOACs (\%) & $16(37)$ & $14(14)$ & 0.0014 \\
\hline Warfarin (\%) & $16(37)$ & $60(59)$ & 0.017 \\
\hline Triple therapy (\%) & $14(33)$ & $30(29)$ & 0.71 \\
\hline Dual therapy (\%) & $29(67)$ & $72(71)$ & 0.71 \\
\hline $\mathrm{PL}_{18}-\mathrm{AUC}_{10}$ & $107[12-200]$ & $146[74-187]$ & 0.097 \\
\hline
\end{tabular}

Data are expressed as $\mathrm{n}(\%)$, means $\pm \mathrm{SD}$, or medians [interquartile range]. Anemia defined as hemoglobin $<13 \mathrm{~g} / \mathrm{dL}$ (male) or $<12 \mathrm{~g} / \mathrm{dL}$ (female); triple therapy defined as dual-antiplatelet therapy plus oral anticoagulants. ACEI, angiotensin-converting enzyme inhibitors; aPTT, activated partial thromboplastin time; ARB, angiotensin-receptor blockers; BMI, body mass index; BMS, bare metal stent; DES, drug-eluting stent; DOACs, direct oral anticoagulants; eGFR, estimated glomerular filtration rate; MI, myocardial infarction; $\mathrm{PCl}$, percutaneous coronary intervention; $\mathrm{PL}_{18}-\mathrm{AUC}_{10}$, area under the flow pressure curve for the first $10 \mathrm{~min}$ for PL-chip tested at flow rate of $18 \mu \mathrm{L} / \mathrm{min}$; PT-INR, prothrombin time-international normalized ratio; TIA, transient ischemic attack.

system developed for easy and quick assessment of thrombus formation under shear stress conditions as previously described.,5,9 Briefly, this system is equipped with a rectangular capillary, a pneumatic pump, and a flow pressure sensor. Thrombus formation is analyzed by continuous monitoring of the flow pressure change resulting from capillary occlusion. Thrombus formation is evaluated with 2 types of microchips: a PL-chip and an AR-chip. The PL- chip contains 25 capillary channels (width, $40 \mu \mathrm{m}$; depth, $40 \mu \mathrm{m}$ ) coated with type I collagen. Inside the microchip, platelets adhere and aggregate on the surface of the collagen, and microchip capillaries are occluded. The AR-chip contains a single capillary channel (width, $300 \mu \mathrm{m}$; depth, $80 \mu \mathrm{m}$ ) coated with type I collagen plus tissue thromboplastin. Inside the microchip, activation of the platelets and the coagulation system is triggered simultaneously by collagen 


\begin{tabular}{|c|c|c|c|}
\hline & OR & $95 \% \mathrm{Cl}$ & $P$ value \\
\hline Age ( $\geq 75$ years) & 1.00 & $0.49-2.06$ & 0.99 \\
\hline Male & 1.81 & $0.62-6.64$ & 0.29 \\
\hline $\mathrm{BMI}^{*}$ & 1.22 & $0.60-2.53$ & 0.58 \\
\hline Current smoking & 1.76 & $0.70-4.27$ & 0.22 \\
\hline Hypertension & 0.91 & $0.39-2.19$ & 0.82 \\
\hline Dyslipidemia & 1.04 & $0.50-2.21$ & 0.91 \\
\hline Diabetes mellitus & 0.90 & $0.43-1.85$ & 0.77 \\
\hline Prior Ml & 0.78 & $0.37-1.68$ & 0.52 \\
\hline Prior PCl & 0.75 & $0.34-1.73$ & 0.50 \\
\hline Stent implantation & 0.80 & $0.38-1.68$ & 0.55 \\
\hline DES & 0.78 & $0.37-1.61$ & 0.51 \\
\hline BMS & 0.83 & $0.36-1.81$ & 0.64 \\
\hline Prior stroke / TIA & 0.85 & $0.22-2.65$ & 0.79 \\
\hline Atrial fibrillation & 1.11 & $0.39-3.66$ & 0.85 \\
\hline CHADS2 score $\geq 2$ & 1.25 & $0.56-2.97$ & 0.60 \\
\hline HAS-BLED score $\geq 3$ & 2.09 & $0.99-4.41$ & 0.052 \\
\hline Baseline anemia & 3.14 & $1.51-6.75$ & 0.0020 \\
\hline Platelet count $^{\star}$ & 1.63 & $0.79-3.38$ & 0.18 \\
\hline eGFR $<60 \mathrm{~mL} / \mathrm{min} / 1.73 \mathrm{~m}^{2}$ & 1.04 & $0.49-2.25$ & 0.93 \\
\hline PT-INR ${ }^{\star \star}$ & 0.70 & $0.34-1.46$ & 0.35 \\
\hline $\mathrm{aPTT}^{\star \star}$ & 1.54 & $0.72-3.35$ & 0.27 \\
\hline Aspirin & 0.50 & $0.20-1.33$ & 0.16 \\
\hline P2Y12 inhibitors & 1.64 & $0.80-3.39$ & 0.17 \\
\hline Clopidogrel & 1.06 & $0.50-2.18$ & 0.88 \\
\hline Prasugrel & 5.35 & $1.34-26.39$ & 0.018 \\
\hline ARB/ACEI & 2.19 & $0.95-5.53$ & 0.067 \\
\hline Statins & 0.70 & $0.29-1.80$ & 0.45 \\
\hline Proton-pump inhibitors & 1.80 & $0.71-5.19$ & 0.22 \\
\hline DOACs & 2.41 & $1.17-5.10$ & 0.017 \\
\hline Warfarin & 0.41 & $0.20-0.86$ & 0.017 \\
\hline Standard dose of DOACs & 3.72 & $1.62-8.72$ & 0.0021 \\
\hline Triple therapy & 1.16 & $0.53-2.47$ & 0.71 \\
\hline $\mathrm{PL}_{18}-\mathrm{AUC}_{10}{ }^{*}$ & 1.86 & $0.91-3.90$ & 0.090 \\
\hline $\mathrm{AR}_{4}-\mathrm{AUC}_{30}{ }^{*}$ & 3.84 & $1.81-8.60$ & 0.0004 \\
\hline
\end{tabular}

*Lower than the median value. ${ }^{*}$ Higher than the median value. $\mathrm{AR}_{4}-\mathrm{AUC}_{30}$, area under the flow pressure curve for the first $30 \mathrm{~min}$ for AR-chip tested at flow rate of $4 \mu \mathrm{L} / \mathrm{min} ; \mathrm{Cl}$, confidence interval; OR, odds ratio. Other abbreviations as in Table 1.

and tissue thromboplastin, respectively. The area under the flow pressure curve (AUC) was analyzed to assess thrombogenicity inside the microchip. The AUC for the first $10 \mathrm{~min}$ for the PL-chip at a flow rate of $18 \mu \mathrm{L} / \mathrm{min}$ is described as PL18-AUC10, and the AUC for the first $30 \mathrm{~min}$ for the AR-chip at a flow rate of $4 \mu \mathrm{L} / \mathrm{min}$ was described as $\mathrm{AR}_{4}-\mathrm{AUC}_{30}$. These pressure-time integrals were used to quantify the overall stability of thrombus. Lower $\mathrm{PL}_{18}-\mathrm{AUC}_{10}$ or $\mathrm{AR}_{4}-\mathrm{AUC}_{30}$ values presumably reflect slow or reduced thrombus growth, or alternatively a rapid breakdown of thrombus. ${ }^{9}$

\section{Clinical Outcomes}

Prognostic information was obtained using electronic medical records or telephone interviews. Bleeding complications were defined as type 1,2,3, or 5 bleeding, according to the Bleeding Academic Research Consortium (BARC) definitions. ${ }^{10}$ Major adverse cardiovascular events (MACE) were defined as death from cardiac cause, myocardial infarction, or ischemic stroke.

\section{Statistical Analysis}

Continuous variables in baseline characteristics are reported as mean $\pm \mathrm{SD}$ or as median (interquartile range [IQR]) and were compared with the use of Student's t-test or the Mann-Whitney U-test. Categorical variables in baseline characteristics are expressed as frequencies (percentages) and were compared by chi-square test. Univariate variables to predict bleeding complications were analyzed, and variables with $\mathrm{P}<0.05$ on univariate analysis were entered into a multivariate logistic regression analysis with the forced entry method. Event-free rates from the time of study entry were estimated by the Kaplan-Meier method and compared by the log-rank test. $\mathrm{P}<0.05$ was considered to indicate statistical significance. All data were analyzed with JMP ${ }^{\circledR} 12$ (SAS Institute Inc., Cary, NC, USA).

\section{Results}

\section{Distribution of T-TAS Parameters}

De-escalation from triple therapy to dual therapy was 
Table 3. Multivariate Logistic Regression Analysis

\section{Model 1}

$\mathrm{AR}_{4}-\mathrm{AUC}_{30}$ *

Baseline anemia

Prasugrel

DOACs

Standard dose of DOACs
3.18 (1.44-7.33), $P=0.0041$

2.33 (1.05-5.25), $P=0.036$

$2.85(0.60-15.98), P=0.19$

2.17 (1.00-4.84), $P=0.051$
Model 2

4.17 (1.79-10.51), $P=0.0008$

4.05 (1.70-10.39), $P=0.0013$

$0.92(0.33-2.46), P=0.87$

7.29 (2.24-26.44), $P=0.0007$

Data are expressed as OR $(95 \% \mathrm{Cl}), \mathrm{P}$ value. * Lower than the median value. Abbreviations as in Tables 1,2.

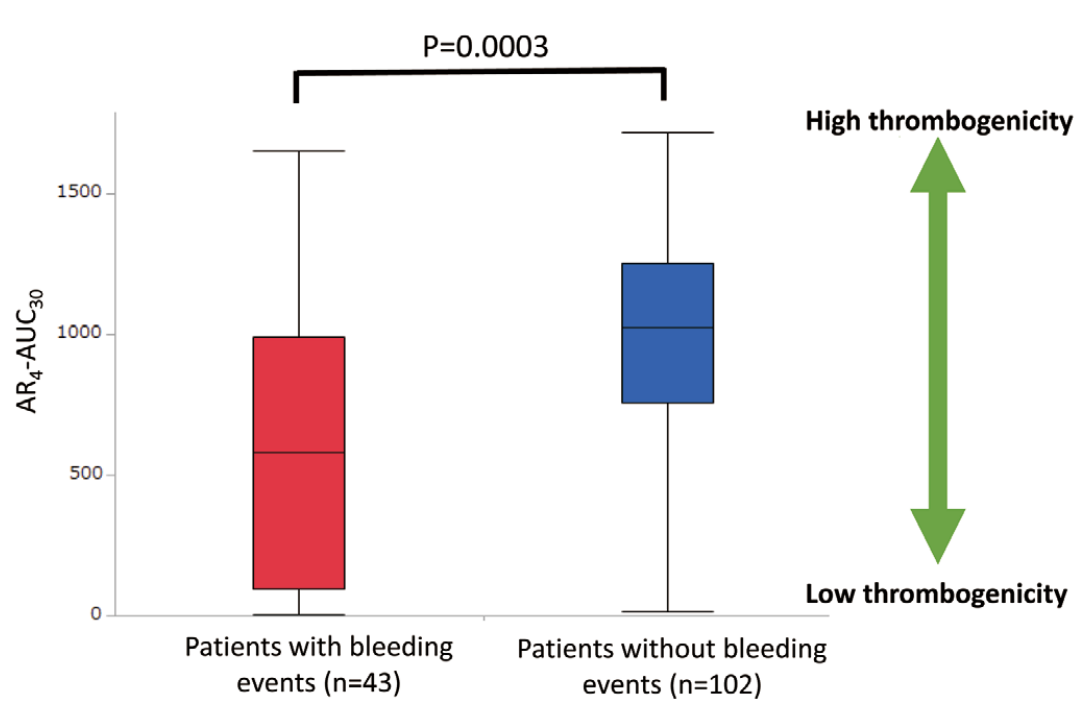

Figure 2. Median $\mathrm{AR}_{4}-\mathrm{AUC}_{30}$ (total thrombogenicity level) is significantly lower in patients with subsequent bleeding events than in those without bleeding events. $\mathrm{AR}_{4}-\mathrm{AUC}_{30}$, area under the flow pressure curve for the first 30 min for the AR-chip tested at a flow rate of $4 \mu \mathrm{L} / \mathrm{min}$. found in 37 patients during the follow-up periods (median time of de-escalation was 85 days). However, escalation from dual therapy to triple therapy was not observed. Bleeding events occurred in 43 patients during an average 22-month follow-up. The definition of BARC 1, 2, and 3 was met $16(37 \%), 18(42 \%)$, and $9(21 \%)$, respectively, of those patients with bleeding events.

Figure 1 shows the distribution of $\mathrm{AR}_{4}-\mathrm{AUC}_{30}$ (median, 967; IQR, 491-1,215) and PL18-AUC 10 (median, 131; IQR, 51-188) in all study patients. The effects of antithrombotic agents assessed using T-TAS widely varied among individuals. There was a weak correlation between $\mathrm{AR}_{4}-\mathrm{AUC}_{30}$ and $\mathrm{PL}_{18}-\mathrm{AUC}_{10}(\mathrm{r}=0.17, \mathrm{P}=0.043)$.

\section{Characteristics of Patients With and Without Bleeding Events}

All subjects were divided into 2 groups according to subsequent bleeding events. Table 1 shows the baseline characteristics of patients with bleeding events $(n=43)$ and those without $(\mathrm{n}=102)$. The proportions of HAS-BLED score $\geq 3$ ( $44 \%$ vs. $27 \%, \mathrm{P}=0.049)$, baseline anemia $(65 \%$ vs. $37 \%$, $\mathrm{P}=0.0021)$, prasugrel use $(14 \%$ vs. $3 \%, \mathrm{P}=0.012)$, usage of DOACs $(63 \%$ vs. $41 \%, \mathrm{P}=0.017)$, and usage of the standard dose of DOACs $(37 \%$ vs. $14 \%, \mathrm{P}=0.0014)$ were significantly higher among patients with bleeding events than those without. There were no significant differences between the 2 groups in other baseline characteristics.

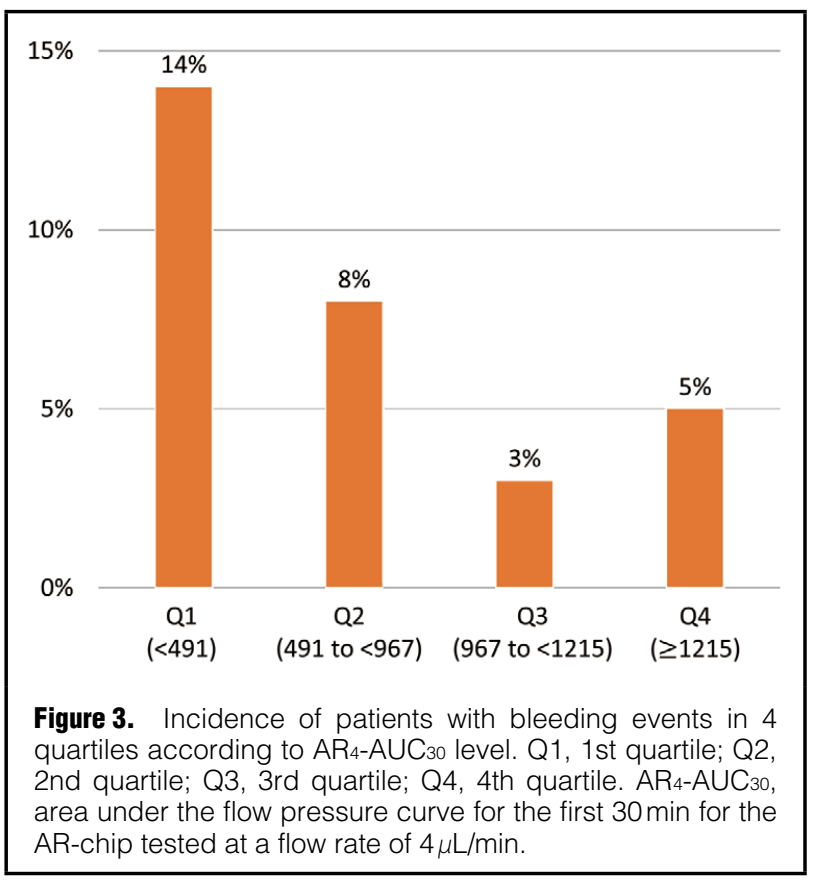

Circulation Journal Vol.83, June 2019 
A

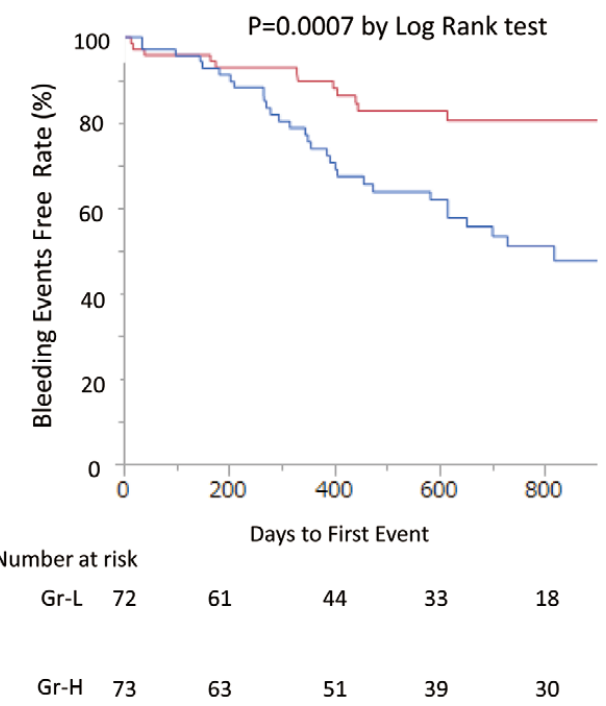

B

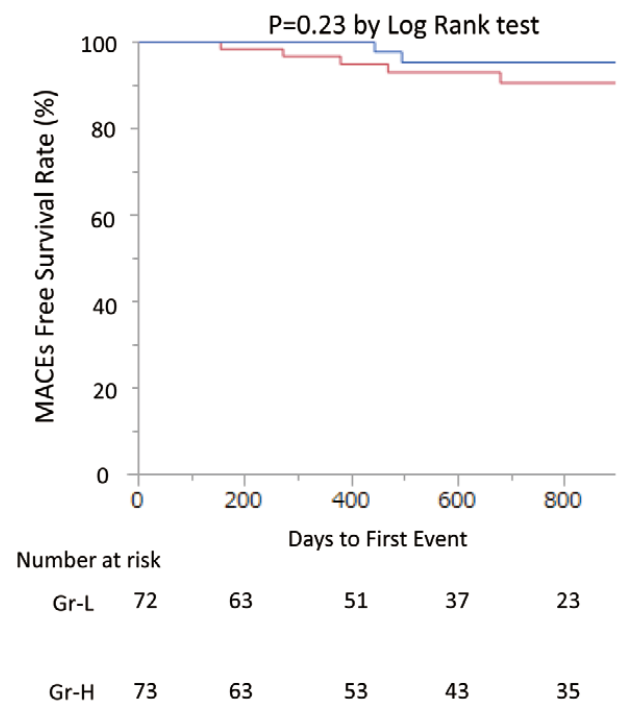

Figure 4. Kaplan-Meier event-free survival curves for bleeding events (A) and MACE (B). MACE was defined as death from cardiac cause, myocardial infarction, or stroke; Gr-H, high thrombogenicity group; Gr-L, low thrombogenicity group. MACE, major adverse cardiovascular events.

\section{Predictors of Bleeding Events}

Univariate logistic regression analysis demonstrated that baseline anemia, prasugrel use, usage of DOACs, usage of the standard dose of DOACs, and $\mathrm{AR}_{4}-\mathrm{AUC}_{30}$ were related to bleeding events (Table 2). However, aPTT, PT-INR, PL18-AUC10, and triple therapy (combination of dualantiplatelet therapy and oral anticoagulants) were not significantly related to bleeding events. Multivariate logistic regression analysis identified $\mathrm{AR}_{4}-\mathrm{AUC}_{30}$, usage of the standard dose of DOACs, and baseline anemia as significant predictors of bleeding events (Table 3).

\section{Impact of Thrombogenicity Measured With T-TAS on Clinical Outcomes}

$\mathrm{AR}_{4}-\mathrm{AUC}_{30}$ was significantly lower in patients with bleeding events than in those without (584 [96-993] vs. 1,028 [756-1,252], $\mathrm{P}=0.0003$ ) (Figure 2). Figure 3 shows the incidence of patients with bleeding events across $\mathrm{AR}_{4}-\mathrm{AUC}_{30}$ quartiles. Approximately three-quarters $(73 \%)$ of patients with bleeding events were in the first and second AR4$\mathrm{AUC}_{30}$ quartiles.

Study patients were also classified into 2 groups according to median $\mathrm{AR}_{4}-\mathrm{AUC}_{30}$ level: low thrombogenicity group (Gr-L, $\mathrm{n}=72$ ) and high thrombogenicity group (Gr-H, n=73). Patients' characteristics and blood examinations in the 2 groups are shown in Supplementary Table. At 22 months, the incidence of bleeding events was significantly higher in Gr-L than in Gr-H (38\% vs. $16 \%$, $\mathrm{P}=0.0007$ ) (Figure 4A). MACE occurred in 8 patients during follow-up; however, there were no significant differences in the incidence of MACE between the 2 groups ( $3 \%$ vs. $5 \%, \mathrm{P}=0.23$ ) (Figure 4B). According to the median $\mathrm{PL}_{18}-\mathrm{AUC}_{10}$, there were no significant differences in the incidence of bleeding events ( $32 \%$ vs. $22 \%, \mathrm{P}=0.18)$ and MACE ( $3 \%$ vs. $5 \%, \mathrm{P}=0.37$ ) between the lower PL18-AUC10 group and higher PL18-AUC10 group.

\section{Discussion}

To our knowledge, this is the first study to assess whether low total thrombogenicity increases the risk of bleeding complications in patients with CAD who receive multiple antithrombotic agents (combination of oral anticoagulants and antiplatelet drugs). In the present study, whole-blood thrombogenicity was assessed using T-TAS; results were expressed as $\mathrm{AR}_{4}-\mathrm{AUC}_{30}$. The effects of antithrombotic agents assessed using the AR-chip varied widely among individuals, and patients with bleeding complications had low on-treatment thrombogenicity compared with those without. In addition, $\mathrm{AR}_{4}-\mathrm{AUC}_{30}$ was an independent predictor of subsequent bleeding events. However, PL18-AUC10, conventional coagulation tests, including aPTT and PTINR, P2Y12 receptor inhibitors use, and triple therapy were not significant predictors of bleeding events.

Currently, available coagulation assays (e.g., rotational thromboelastometry, thromboelastography) are mostly performed under static conditions, so the complex interactions among erythrocytes, platelets, white blood cells, and coagulation factors under various shear rates cannot be appreciated. Other systems with high shear rates, including the Platelet Function Analyzer and the Cone and Plate analyzer are available to assess platelet adhesion and aggregation; however, their results do not provide information beyond primary hemostasis. ${ }^{11}$ In addition, the present study showed that $\mathrm{PL}_{18}-\mathrm{AUC}_{10}$ as the result of platelet adhesion and aggregation tests was not related to clinical outcomes. In contrast, the AR-chip, which is novel and easy to use for quantitative monitoring of the levels of thrombogenicity under a whole-blood flow state, is a potential tool for the assessment of platelet activation and 
the coagulation system in patients receiving various types of antithrombotic therapy. ${ }^{12,13}$

It has been demonstrated that patients receiving multiple antithrombotic agents have higher rates of bleeding complications, and patients with bleeding complications are associated with poor clinical outcomes compared with those without bleeding complications. ${ }^{14}$ Therefore, guidelines recommend that duration of triple therapy should be minimized according to bleeding and ischemic risks. ${ }^{15}$ Although approximately $6-8 \%$ of patients undergoing PCI have an indication for long-term oral anticoagulants for various conditions such as AF, mechanical heart valves, or venous thromboembolism, these patients should be considered at high risk of bleeding, and the indication for oral anticoagulants or antiplatelet therapy should be reassessed and treatment continued only if a compelling indication exists (e.g., high CHADS2 score, presence of mechanical heart valves, a history of recurrent venous thromboembolism, complexity of treated CAD, or a history of stent thrombosis). ${ }^{15}$ However, the optimal strategy to balance prevention of thrombosis with the risk of bleeding is unclear. ${ }^{16,17}$ The dose intensity of vitamin $\mathrm{K}$ antagonist should be carefully monitored, with the PT-INR in the lower part of the recommended target range. In patients receiving DOACs, it is difficult to monitor the antithrombotic effect.18-21 Our study showed that usage of the standard dose of DOACs as part of multiple antithrombotic therapy was a significant predictor of bleeding events. Some studies suggest a low dose of DOACs as part of a combination of antiplatelet therapy has a favorable outcome, although those studies were underpowered for the assessment of meaningful differences in the incidence of relevant ischemic events.,15,22 In addition, the use of prasugrel or ticagrelor as part of triple therapy should be avoided. ${ }^{23}$

Recent studies have prompted efforts to seek new therapeutic strategies. ${ }^{24-26}$ Three new promising approaches have emerged to reduce the risk of bleeding among patients for whom oral anticoagulants and antiplatelet therapy are indicated., 3,422 These studies demonstrated that a combination of oral anticoagulants and single-antiplatelet therapy was associated with a lower rate of clinically significant bleeding than was standard therapy with oral anticoagulants plus dual-antiplatelet therapy in patients with an indication for oral anticoagulants who underwent PCI. However, clinically significant bleeding complications occurred in approximately $15 \%$ of study patients even in the dual-therapy groups (oral anticoagulants+single-antiplatelet therapy) within the first year of treatment., ,4,22 $^{-4}$ Therefore, a useful methodology for assessing the effects of multiple antithrombotic agents is desirable to avoid bleeding complications.

Ito et al report that thrombogenicity measured with T-TAS using the AR-chip is useful for assessing the efficacy of vitamin $\mathrm{K}$ antagonists and DOACs in AF patients who have undergone catheter ablation and that this marker could be useful for predicting periprocedural bleeding complications. ${ }^{7}$ In the present study, $\mathrm{AR}_{4}-\mathrm{AUC}_{30}$ was a potentially useful marker of future bleeding events in patients with CAD receiving oral anticoagulants plus single- or dual-antiplatelet therapy, although conventional laboratory data such as aPTT and PT-INR were not.

\section{Study Limitations}

First, this single-center, observational study included a relatively small number of patients. Thus, the sample size was too small to evaluate ischemic outcomes. Further, large population studies are needed to evaluate the relationship between AR4-AUC30 measured with T-TAS and rates of ischemic complications. Second, we did not obtain baseline $\mathrm{AR}_{4}-\mathrm{AUC}_{30}$ values before the administration of any antithrombotic agents in our study. However, AR4$\mathrm{AUC}_{30}$ levels in the present study were lower than those in healthy volunteers in previous reports. ${ }^{5}$ In addition, we did not evaluate serial measurements of peak and trough values in patients receiving DOACs. However, all blood samples from patients receiving DOACs were obtained $2-4 \mathrm{~h}$ after taking DOACs, which were estimated as the peak values, and those of patients receiving vitamin $\mathrm{K}$ antagonists were obtained after warfarin doses were fixed in the steady state. It remains unclear whether the peak or trough point of blood sampling is more strongly related to bleeding complications in patients receiving DOACs. ${ }^{27-30}$ Moreover, we did not assess the plasma concentrations of DOACs, anti-Xa activity, or the relationship between T-TAS parameters and the concentrations of DOACs or anti-Xa activity. Furthermore, there was no significant difference in the frequency of triple therapy between patients with and without bleeding complications. This finding might be related to the low intensity of vitamin K antagonist therapy and frequent use of underdosing of DOACs in patients treated with triple therapy. As shown in the present study, there is inter-individual variability in the intensity of oral anticoagulants plus antiplatelet agents. Another explanation is that some patients with triple therapy were switched to dual therapy. Finally, 37\% of patients with bleeding complications had minimal bleeding. Despite these limitations, the results of the present study are expected to contribute to bleeding risk stratification in CAD patients receiving multiple antithrombotic agents.

\section{Conclusions}

Total effects of antithrombotic agents measured with T-TAS widely varied among individuals. The AR4-AUC 30 level was an independent and significant marker for predicting subsequent bleeding complications in stable CAD patients treated with a combination of oral anticoagulants and antiplatelet agents.

\section{Acknowledgment}

The authors thank Ms. Takako Matsushita for her assistance.

\section{Disclosures}

The authors have reported that they have no relationships relevant to the contents of this paper to disclose.

\section{References}

1. Lip GY, Windecker S, Huber K, Kirchhof P, Marin F, Ten Berg JM, et al. Management of antithrombotic therapy in atrial fibrillation patients presenting with acute coronary syndrome and/or undergoing percutaneous coronary or valve interventions: A joint consensus document of the European Society of Cardiology Working Group on Thrombosis, European Heart Rhythm Association (EHRA), European Association of Percutaneous Cardiovascular Interventions (EAPCI) and European Association of Acute Cardiac Care (ACCA) endorsed by the Heart Rhythm Society (HRS) and Asia-Pacific Heart Rhythm Society (APHRS). Eur Heart J 2014; 35: 3155-3179.

2. Paikin JS, Wright DS, Crowther MA, Mehta SR, Eikelboom JW Triple antithrombotic therapy in patients with atrial fibrillation and coronary artery stents. Circulation 2010; 121: 2067-2070. 
3. Dewilde WJM, Oirbans T, Verheugt FWA, Kelder JC, De Smet BJGL, Herrman JP, et al. Use of clopidogrel with or without aspirin in patients taking oral anticoagulant therapy and undergoing percutaneous coronary intervention: An open-label, randomised, controlled trial. Lancet 2013; 381: 1107-1115.

4. Gibson CM, Mehran R, Bode C, Halperin J, Verheugt FW, Wildgoose $\mathrm{P}$, et al. Prevention of bleeding in patients with atrial fibrillation undergoing PCI. N Engl J Med 2016; 375: 2423-2434.

5. Hosokawa K, Ohnishi T, Kondo T, Fukasawa M, Koide T, Maruyama I, et al. A novel automated microchip flow-chamber system to quantitatively evaluate thrombus formation and antithrombotic agents under blood flow conditions. J Thromb Haemost 2011; 9: 2029-2037.

6. Hosokawa K, Ohnishi T, Sameshima H, Miura N, Ito T, Koide $\mathrm{T}$, et al. Analysing responses to aspirin and clopidogrel by measuring platelet thrombus formation under arterial flow conditions. Thromb Haemost 2013; 109: 102-111.

7. Ito M, Kaikita K, Sueta D, Ishii M, Oimatsu Y, Arima Y, et al. Total Thrombus-Formation Analysis System (T-TAS) can predict periprocedural bleeding events in patients undergoing catheter ablation for atrial fibrillation. J Am Heart Assoc, doi:10.1161/JAHA.115.002744.

8. Yamaguchi Y, Moriki T, Igari A, Matsubara Y, Ohnishi T, Hosokawa K, et al. Studies of a microchip flow-chamber system to characterize whole blood thrombogenicity in healthy individuals. Thromb Res 2013; 132: 263-270.

9. Hosokawa K, Ohnishi T, Fukasawa M, Kondo T, Sameshima $\mathrm{H}$, Koide T, et al. A microchip flow-chamber system for quantitative assessment of the platelet thrombus formation process. Microvasc Res 2012; 83: 154-161.

10. Mehran R, Rao SV, Bhatt DL, Gibson CM, Caixeta A, Eikelboom J, et al. Standardized bleeding definitions for cardiovascular clinical trials: A consensus report from the Bleeding Academic Research Consortium. Circulation 2011; 123: $2736-$ 2747.

11. Schott U, Johansson PI II. Bringing flow into haemostasis diagnostics. Br J Anaesth 2013; 111: 864-867.

12. Arima Y, Kaikita K, Ishii M, Ito M, Sueta D, Oimatsu Y, et al. Assessment of platelet-derived thrombogenicity with the total thrombus-formation analysis system in coronary artery disease patients receiving antiplatelet therapy. J Thromb Haemost 2016; 14: $850-859$.

13. Yamazaki M, Ohnishi T, Hosokawa K, Yamaguchi K, Yoneyama T, Kawashima A, et al. Measurement of residual platelet thrombogenicity under arterial shear conditions in cerebrovascular disease patients receiving antiplatelet therapy. $J$ Thromb Haemost 2016; 14: 1788-1797.

14. Nikolsky E, Stone GW, Kirtane AJ, Dangas GD, Lansky AJ, McLaurin B, et al. Gastrointestinal bleeding in patients with acute coronary syndromes: Incidence, predictors, and clinical implications: Analysis from the ACUITY (Acute Catheterization and Urgent Intervention Triage Strategy) trial. $J$ Am Coll Cardiol 2009; 54: $1293-1302$.

15. Valgimigli M, Bueno H, Byrne RA, Collet JP, Costa F, Jeppsson A, et al. 2017 ESC focused update on dual antiplatelet therapy in coronary artery disease developed in collaboration with EACTS Kardiol Pol 2017; 75: 1217-1299.

16. Levine GN, Bates ER, Bittl JA, Brindis RG, Fihn SD, Fleisher LA, et al. 2016 ACC/AHA Guideline Focused Update on Duration of Dual Antiplatelet Therapy in Patients With Coronary Artery Disease: A Report of the American College of Cardiology/ American Heart Association Task Force on Clinical Practice Guidelines: An Update of the 2011 ACCF/AHA/SCAI Guideline for Percutaneous Coronary Intervention, 2011 ACCF/AHA Guideline for Coronary Artery Bypass Graft Surgery, 2012 ACC/AHA/ACP/AATS/PCNA/SCAI/STS Guideline for the Diagnosis and Management of Patients With Stable Ischemic Heart Disease, 2013 ACCF/AHA Guideline for the Management of ST-Elevation Myocardial Infarction, 2014 AHA/ACC Guideline for the Management of Patients With Non-STElevation Acute Coronary Syndromes, and 2014 ACC/AHA
Guideline on Perioperative Cardiovascular Evaluation and Management of Patients Undergoing Noncardiac Surgery. Circulation 2016; 134: e123-e155.

17. Steg PG, Bhatt DL. Viewpoint: A proposal for a simple algorithm for managing oral anticoagulation and antiplatelet therapy in patients with non-valvular atrial fibrillation and coronary stents. Eur Heart J Acute Cardiovasc Care 2017; 6: 93-97.

18. van Ryn J, Stangier J, Haertter S, Liesenfeld KH, Wienen W, Feuring M, et al. Dabigatran etexilate: A novel, reversible, oral direct thrombin inhibitor: Interpretation of coagulation assays and reversal of anticoagulant activity. Thromb Haemost 2010; 103: $1116-1127$.

19. Kubitza D, Becka M, Voith B, Zuehlsdorf M, Wensing G. Safety, pharmacodynamics, and pharmacokinetics of single doses of BAY 59-7939, an oral, direct factor Xa inhibitor. Clin Pharmacol Ther 2005; 78: 412-421.

20. Kanemoto M, Kuhara H, Ueda T, Shinohara T, Oda T, Nakao $\mathrm{F}$, et al. Association of apixaban therapy and prothrombin time in patients with atrial fibrillation. Circ J 2014; 78: 2651-2656.

21. Samama MM, Mendell J, Guinet C, Le Flem L, Kunitada S. In vitro study of the anticoagulant effects of edoxaban and its effect on thrombin generation in comparison to fondaparinux. Thromb Res 2012; 129: e77-e82.

22. Cannon CP, Bhatt DL, Oldgren J, Lip GYH, Ellis SG, Kimura $\mathrm{T}$, et al. Dual antithrombotic therapy with dabigatran after PCI in atrial fibrillation. $N$ Engl J Med 2017; 377: 1513-1524.

23. Sarafoff N, Martischnig A, Wealer J, Mayer K, Mehilli J, Sibbing D, et al. Triple therapy with aspirin, prasugrel, and vitamin $\mathrm{K}$ antagonists in patients with drug-eluting stent implantation and an indication for oral anticoagulation. $\mathrm{J} \mathrm{Am}$ Coll Cardiol 2013; 61: 2060-2066.

24. Andrade JG, Deyell MW, Khoo C, Lee M, Humphries K, Cairns JA. Risk of bleeding on triple antithrombotic therapy after percutaneous coronary intervention/stenting: A systematic review and meta-analysis. Can J Cardiol 2013; 29: 204-212.

25. Lamberts M, Olesen JB, Ruwald MH, Hansen CM, Karasoy D, Kristensen SL, et al. Bleeding after initiation of multiple antithrombotic drugs, including triple therapy, in atrial fibrillation patients following myocardial infarction and coronary intervention: A nationwide cohort study. Circulation 2012; 126: 11851193.

26. Lemesle G, Ducrocq G, Elbez Y, Van Belle E, Goto S, Cannon $\mathrm{CP}$, et al. Vitamin $\mathrm{K}$ antagonists with or without long-term antiplatelet therapy in outpatients with stable coronary artery disease and atrial fibrillation: Association with ischemic and bleeding events. Clin Cardiol 2017; 40: 932-939.

27. Reilly PA, Lehr T, Haertter S, Connolly SJ, Yusuf S, Eikelboom JW, et al. The effect of dabigatran plasma concentrations and patient characteristics on the frequency of ischemic stroke and major bleeding in atrial fibrillation patients: The RE-LY Trial (Randomized Evaluation of Long-Term Anticoagulation Therapy). J Am Coll Cardiol 2014; 63: 321 - 328.

28. Leil TA, Feng Y, Zhang L, Paccaly A, Mohan P, Pfister M. Quantification of apixaban's therapeutic utility in prevention of venous thromboembolism: Selection of phase III trial dose. Clin Pharmacol Ther 2010; 88: 375-382.

29. Sakaguchi T, Osanai H, Murase Y, Ishii H, Nakashima Y, Asano H, et al. Monitoring of anti-Xa activity and factors related to bleeding events: A study in Japanese patients with nonvalvular atrial fibrillation receiving rivaroxaban. J Cardiol 2017; 70: 244-249.

30. Weitz JI, Connolly SJ, Patel I, Salazar D, Rohatagi S, Mendell $\mathrm{J}$, et al. Randomised, parallel-group, multicentre, multinational phase 2 study comparing edoxaban, an oral factor Xa inhibitor, with warfarin for stroke prevention in patients with atrial fibrillation. Thromb Haemost 2010; 104: 633-641.

\section{Supplementary Files}

Please find supplementary file(s);

http://dx.doi.org/10.1253/circj.CJ-18-1236 